\title{
Prysverlagings op voorraad met 'n dalende vraag
}

\author{
SE Visagie* \\ Ontvang: 5 Februarie 2003; Hersien: 31 Oktober 2004; Aanvaar: 8 November 2004
}

\section{Opsomming}

Hierdie artikel stel 'n heuristiese benadering voor om die verliese op voorraad met 'n dalende vraag en onbekende tydshorison te minimeer. Die twee metodes wat voorgestel word, gebruik 'n benaderde vraagkromme om die verwagte verliese te voorspel. Albei heuristieke gebruik hierdie vooruitskatting om te bepaal wanneer die prys van items in voorraad afgemerk moet word ten einde verkope te versnel om verliese te vermy wat as gevolg van lang omsettye ontstaan. 'n Gevallestudie wat die werklike data van 'n CD-winkel simuleer, word gebruik om die twee heuristieke se prestasie relatief tot die huidige afmerkstrategie van die bestuur te meet.

Sleutelwoorde: Voorraad, oorbodigheid, periodiese pryshersienings, pryselastisiteit, simulasie, heuristiek

\begin{abstract}
The problem faced in this paper is a periodic pricing of inventory with obsolescence and an unknown time horizon. Typical inventory items with these properties are music CDs. The periodic pricing of music CDs is used as a tool to manipulate the demand thereof as they become less popular. A CD will, however, not perish in the time it is kept as inventory, as is the case with perishable inventory. This property accounts for the obsolescence. Other kinds of items in inventory that also become obsolete are typical fashion goods, like clothes. Contrary to CDs the demand for these goods do have a known time horizon (usually at the end of a season).

The paper starts out by giving an introduction to the problems faced in a CD shop. Background information is given on how CD shops operate. The method of pricing CDs is explained. The current policy at a CD shop of when, and how many orders are placed is explained. This introduction is followed by an overview of relevant literature on various types of inventory problems. The review is structured according to the three properties of the problem. The first property is the pricing of items in inventory. The second property is that items in inventory may be considered as inventory with a random lifetime. The third property is that the items in inventory become obsolete.

The subject of the pricing of inventory has received substantial attention in the operations research literature over the years. The conclusion after consultation of the references on the periodic pricing of inventory is that all these articles have two characteristics in common: the time horizon of the items in inventory are considered to be fixed and it is known by how much the price will change. In the problem under consideration only the second characteristic may be assumed. The objective in most of the literature is to find the time when, and how many times the price should be changed.
\end{abstract}

${ }^{*}$ Departement Logistiek, Universiteit van Stellenbosch, Privaatsak X1, Matieland, 7602, Stellenbosch, Suid-Afrika, e-pos: svisagie@sun.ac.za 
The second property deals with inventory with a stochastic lifetime. By far the most literature on inventory with a stochastic lifetime appears under the banner of perishable inventory. Perishable inventory consist of inventories that deteriorates (damage, spoil, vaporise, etc.) as time elapses, regardless of how intensively it is used.

Perishable inventory may be classified into three main groups, namely inventory with a fixed lifetime (sell-by date), stochastic lifetime inventory and inventory that deteriorates according to some law (for example, proportional to the number of items in inventory). CDs fall into the middle group, but do not deteriorate as such. A rich body of literature exists on the subject of perishable inventory with a stochastic lifetime. In this literature the main objective is to determine the optimal order quantity and reorder point. This is because deteriorating inventory is replaced by the same product on the shelf, which is not the case with CDs. CDs are replaced with a different product once it has become obsolete. This body of literature is thus not very relevant to this study, because the aim of the study is not to find optimal order quantities or reorder points, but the points in time at which the prices should be changed. The third property is obsolescence. Very little was found on this subject in the literature and most of the existing work considered clearance sales at the end of a season. A problem where these three properties are combined could not be found.

Two heuristic approaches to minimise the loss made on inventory with the properties as described above, are presented. The first heuristic was developed in conjunction with the manager of a CD shop. This method allows one to set a date $\left(T_{0}\right)$ when the demand for a $\mathrm{CD}$ will vanish. The heuristic predicts whether or not the inventory in hand will be sold out before that date at the current price. If not, the price should be lowered. This method allows the manager to answer "what if" questions, by fixing $T_{0}$ at different values. The second heuristic does not require manual input. It calculates the time $\left(T\left(P_{i}\right)\right)$ when the inventory carrying cost is equal to the selling price less the buying price (profit), because after this point the CD must be sold at a loss. The heuristic then predicts the sales and calculates whether the inventory in hand will be sold out before or after $T\left(P_{i}\right)$. If the inventory cannot be sold out before $T\left(P_{i}\right)$, the price should be lowered to increase the demand.

Finally a case study is presented. The performance of the different demand curves are tested with a simulation of actual data from a CD shop to measure the performance of the heuristics against the current mark-down strategies followed. The conclusion is that both heuristics outperform the current pricing policy of the shop management.

Key words: Inventory, obsolescence, periodic price reviews, price elasticity, simulation, heuristic

\section{$1 \quad$ Inleiding}

'n Algemene vraag vir 'n kleinhandelaar is wanneer om die prys van verkoopsvoorraad af te merk. Heelwat navorsing is al oor hierdie onderwerp gedoen. Hierdie navorsing is meestal op die gebied van bederfbare voorraad en seisoenale of modeprodukte [28] gedoen. Die groot voordeel van hierdie tipes produkte is dat hulle almal 'n relatief bekende tydshorison het. Die tyd wat 'n sekere vrug byvoorbeeld op die rak kan bly sonder om te bederf, is bepaalbaar. Met seisoenale produkte, soos klere, kan ook vasgestel word wanneer die vraag na hierdie produkte gaan opdroog, naamlik die einde van die seisoen. Daar is egter 'n ander tipe produk, soos CD's, wat nie die eienskap het dat 'n tydshorison bepaal kan word nie. Die duur van 'n nuut-uitgereikte CD se gewildheid is onseker en daarom spekulatief. Al wat ons van so 'n produk weet, is dat die vraag na die produk na verloop van tyd gaan daal. Die vraag ontstaan nou: Wanneer moet die prys van hierdie produk verminder word?

In die hoogs mededingende mark van CD-verkope is dit vir die bestuurder van 'n winkel belangrik om die voorraad, sowel as die bepaling van CD-pryse, so goed moontlik te bestuur. 
Hierdie twee faktore word dwingender indien die winkel nie aan 'n kettinggroep behoort wat voordele soos sentrale voorraadbeheer, sentrale aankope en sentrale bemarking van die produk bied nie. Hierdie probleem word nog meer kritiek as in ag geneem word dat CD's hoogs vervangbare produkte is. Dit bring vir die verbruiker baie min ongerief mee om dieselfde CD by 'n ander winkel of selfs oor die internet te koop. Die kwaliteit van die produk is by alle winkels presies dieselfde; dus kan 'n winkel nie onderskei word van sy mededingers op grond van die kwaliteit van die produk nie. Die enigste gebiede waarop 'n winkel dus onderskei kan word, is op grond van prys en diens. Aangesien die CD-bedryf baie kompeterend is kan 'n winkel nie prysbepaling onafhanklik van die kompetisie doen nie. In die praktyk word gevind dat die meeste handelaars min of meer dieselfde prys vir 'n nuwe CD vra. Die bepaling van die prys van 'n nuwe CD is dus nie so 'n groot probleem nie. Wat wel 'n groot probleem is, is watter strategie van prysverlagings gevolg moet word nadat die verkope van die CD sodanig getaan het dat bestuurders moontlik nie al hulle voorraad kan verkoop nie, of die voorraad so lank op die rakke is dat die voorraaddrakoste meer word as die wins.

CD-handelaars baseer hulle besluite in verband met die hoeveelheid wat van 'n sekere CD te bestel moet word op verskeie faktore. Die belangrikste faktore is (1) die kunstenaar (of groep) wat ter sprake is, (2) die tyd wat kettinggroepe aan advertensies vir die spesifieke CD afstaan (aangesien dit ook hulle winkel se verkope beïnvloed), (3) die lugtyd wat die CD op radio en televisie kry, (4) die ouderdom van die CD, en (5) wanneer die kunstenaar (of groep) 'n konserttoer gaan onderneem. Die verkope van 'n kunstenaar se CD neem gewoonlik skerp toe tydens konserttoere in die omgewing. Die bestuurder kan enige tyd gedurende die week bestel, en die afleweringstyd is nagenoeg konstant en gelyk aan vier werksdae. Bestellings word sover moontlik aan die einde van 'n maand geplaas om gebruik te maak van die volle 60 dae-betaaltydperk wat verskaffers bied. Die bedrag waarmee 'n CD in die praktyk afgemerk word, is ook redelik gevestig. Die prys word twee keer afgemerk en daarna word die CD teen daardie prys op die rak gehou. Indien die CD's steeds nie verkoop nie, word 'n uitverkoping gehou.

In die volgende afdeling word 'n oorsig oor die relevante literatuur rakende hierdie probleem gegee. In $\S 3$ word heuristiese algoritmes wat verliese in 'n CD-winkel minimeer, ontwikkel. 'n Gevallestudie in $\S 4$ illustreer die gebruik van hierdie heuristieke, en $\S 5$ bevat gevolgtrekkings en voorstelle vir verdere studie.

\section{Literatuuroorsig}

Daar is heelwat werk gepubliseer op die gebied van voorraadbeheer. Baie van hierdie werk is op die gebied van ekonomie en bemarking [8, 24]. In die vakgebied van operasionele navorsing is daar net so 'n ryk literatuur. Van die werk wat oor voorraadbeheer in hierdie kringe gepubliseer is, is gemoeid met die bestelhoeveelhede en herbestelpunte van bederfbare produkte [32], of die wedersydse invloed van die prys van die items in voorraad op hierdie groothede [9]. Die ander onderwerp wat ook herhaalde kere ondersoek word, is die bestuur van uitverkopings $[3,34]$. Die bepaling van lotgroottes van bederfbare produkte het veral in die laaste aantal jare baie aandag gekry $[1,33]$. Bogenoemde metodes is egter nie geskik vir CD's nie, aangesien die CD's nadat dit "bederf" het, nie weer aangevul word 
nie, maar met 'n ander (nuwe) produk vervang word. Bederfbare produkte, daarenteen, word met dieselfde produk vervang. Die bestaande publikasies fokus dus op vrae soos die hoeveelheid wat van 'n bederfbare produk aangekoop moet word en wanneer dit moet geskied. Hierdie vrae is nie so kritiek in 'n CD-winkel nie. Die afleweringstyd in die geval van CD's is relatief kort en die bestelkoste laag, wat beteken dat bestellings gereeld geplaas kan word.

Indien die voorraadmodelle beskou word wat slegs voorraad wat verval in ag neem, ontstaan daar twee duidelike groepe, nl. voorraad wat oorbodig raak en voorraad wat bederf. Voorraad wat oorbodig raak is voorraad wat byvoorbeeld uit die mode raak of tegnologie wat verouder. Voorraad wat bederf is voorraad wat oor tyd versleg (bv. verrot) of agteruit gaan. Oor die tweede groep is daar baie navorsing gedoen, terwyl die eerste groep feitlik geen aandag geniet nie [13]. Die probleem wat in hierdie studie hanteer word, het drie eienskappe, naamlik die prys moet van tyd tot tyd hersien word, die tydshorison is stogasties en die produk raak oorbodig. Hierdie drie eienskappe word vervolgens vanuit die literatuur beskou.

Volgens Chatwin (2000) is die eerste werk oor die optimale beprysing van produkte deur Kincaid en Darling (1963) gepubliseer. Hulle het, soos in hierdie studie, aangeneem dat daar 'n vaste aantal pryse tot die besluitnemer se beskikking is, maar hulle het 'n definitiewe tydshorison gebruik. Dinamiese programmering is gebruik om 'n oplossing te bepaal. Miller (1968) het voortgebou op Kincaid en Darling se werk, maar het die eindige tydshorison behou. Hy het aangetoon dat die optimale prysstrategie stuksgewys konstant is. Nahmias (1982) het 'n oorsigartikel oor voorraad wat verval, gepubliseer. Die gevolgtrekking aan die einde van sy artikel is dat die bepaling van 'n prysstruktuur vir bederfbare produkte waarvolgens halfbederfde produkte teen 'n laer prys verkoop word, 'n ope vraag is. Gallego en Van Ryzin (1997) het van die standpunt uitgegaan dat 'n kontinue verandering van die prys van 'n item onprakties is en het 'n aantal vaste prysbeleide se prestasie met mekaar vergelyk. Hulle het ook 'n heuristiek voorgestel waarvolgens die prys beheer kan word, mits die aantal pryse waarteen die produk verkoop kan word en die tydshorison vas is. Hierdie heuristiek se prestasie is, soos in hierdie studie, teen bestaande beleide getoets, en daar is voorgestel dat daar 'n maksimum van een prysverandering moet wees. Feng en Gallego (1995) het hierdie heuristiek verder gevoer en die optimale tyd probeer vasstel waarop hierdie enkele prysverandering (verhoging of verlaging) moet plaasvind. Bitran en Mondschein (1997) het op hierdie werk uitgebrei deur optimale beleide daar te stel vir wat hulle gedefinieer het as periodiese pryshersienings. Dit is die agtereenvolgende prysverlagings op diskrete intervalle gedurende 'n seisoen tot by 'n uitverkoping aan die einde van die tydshorison. Hulle studie het op kleinhandelgroepe gefokus. Deur diskrete intervalle te definieer, word daar van die kontinue probleem ontslae geraak. Hierdie werk is verder uitbrei deur Bitran et al. (1998) in die geval van kettingwinkels. Hulle het ook heuristiese oplossings voorgestel wat teen bestaande beleide getoets is. In dieselfde jaar het Smith en Achabal (1998) werk gepubliseer wat meer fokus op die laaste uitverkoping. Chatwin (2000) het op hierdie werk voortgebou deur 'n optimale dinamiese beprysing vir bederfbare produkte te bepaal. Hy aanvaar ook dat daar 'n eindige stel pryse beskikbaar is. Onder 'n aantal korrekte aannames bewys Chatwin dat daar 'n bogrens (maksimum) op die aantal prysveranderinge van 'n item is. Al hierdie werk het egter twee eienskappe gemeen, naamlik die tydshorison vir die verval van die produk is vas, en die aantal en 
grootte van die prysveranderinge is vas.

Die navorsing oor bederfbare produkte kan in drie kategorieë verdeel word [13]. Eerstens modelle vir voorraad met 'n vaste leeftyd, dan modelle vir voorraad met 'n stogastiese leeftyd en laastens modelle vir voorraad wat bederf proporsioneel tot 'n grootheid, soos die hoeveelheid items in voorraad. Uit hierdie kategorieë is die voorraad met 'n stogastiese leeftyd vir hierdie studie van belang. Voorraad met 'n stogastiese leeftyd is voorraad waarvan die leeftyd nie vooruit bepaal kan word nie [13]. Hierdie definisie plaas CD's dus in hierdie kategorie. 'n Hele aantal $(s, S)$ sisteme met 'n onmiddellike afleweringstyd is vir voorraad met 'n stogastiese leeftyd ontwikkel [14, 16, 25]. Moorthy et al. (1992) het 'n model ontwikkel waarin 'n item van die produk op die rak geplaas word eers nadat die vorige item verkoop is. Die items begin verval sodra hulle op die rak geplaas word. Jain en Silver (1994) het dinamiese programmering gebruik om die optimale bestelhoeveelheid vir 'n produk met 'n stogastiese leeftyd te bepaal. Kalpakam en Sapna (1994) het optimale bestelhoeveelhede bepaal onder die aannames dat die leeftyd van items stogasties en die afleweringstye daarvan eksponensieel verdeel is. Kalpakam en Sapta het in latere werk $[18,19]$ op hierdie model uitgebrei. Liu en Cheung (1997) het die eksponensiële leeftye behou, maar oorstaanbestellings in die model ingevoer. Later het Liu en Shi (1999) verder op hierdie model uitgebrei deur die vraag met 'n Markov-proses te modelleer. Ander variasies van die probleem wat ook ondersoek is, is byvoorbeeld Wee en Yu (WeeYu1997) wat ondersoek ingestel het na die wyse waarop grootmaatafslag beïnvloed word indien die voorraad bederf. Die hoofdoelwit in al hierdie modelle is om die optimale herbestelpunt en bestelgrootte vir bederfbare produkte met 'n stogastiese leeftyd te bepaal.

Literatuurstudie oor voorraad wat oorbodig raak, het getoon dat baie min oor hierdie onderwerp gepubliseer is. Dit is ook Goyal en Giri (GoyGir2001) se bevinding in hulle oorsigartikel oor die moderne ontwikkelings in die modellering van bederfbare voorraad. Goyal en Giri verwys die leser terug na Nahmias (1982) vir verdere verwysings en ondersoek in verband met voorraad wat oorbodig raak. Hierdie artikel van Nahmias was toe reeds twintig jaar oud, wat 'n aanduiding is dat daar nie veel aandag aan hierdie tipe probleem geskenk is nie. Navorsing in hierdie kategorie het begin met die werk van Whitin (1957) wat hoofsaaklik modeprodukte beskou het. 'n Model wat ekponensiële verval gebruik het, is deur Ghare en Schrader (1963) ontwikkel, nadat hulle gevind het dat baie produkte wat oorbodig raak die eienskappe van eksponensiële verval toon. Cobbaert en Oudheusden (1996) se artikel is die enigste ná Nahmias wat hierdie tipe probleem ondersoek het. Hulle het vinnigbewegende voorraaditems beskou wat 'n "skielike dood"oorbodigheid vertoon. Hierdie tipe voorraad het die risiko dat dit skielik, volgens 'n sekere waarskynlikheidsverdeling, oorbodig kan raak. Hulle het dus modelle ontwikkel wat hierdie risiko, sowel as voorraadtekorte kan hanteer.

Die probleem om pryse te gebruik ten einde voorraad wat 'n (relatief) vaste tydshorison het, te verkoop, is goed ondersoek en staan bekend as periodiese pryshersienings. Die probleem van wanneer en hoeveel bestel moet word van voorraad wat volgens 'n stogastiese proses bederf, is ook deeglik ondersoek. Die probleem wat hier ondersoek word, naamlik hoe om ouer voorraad (waarvan die tydshorison onbekend is) se omset te versnel om sodoende verliese te vermy, is sover vasgestel kon word, nog nie ondersoek nie. 


\section{Die model}

Laat die prys waarteen voorraad verkoop word, $P_{i}$ wees. Die prys ná 'n prysverlaging sal dan $P_{i+1}$ wees, met $i=1,2, \ldots$ Dit beteken $P_{1}$ sal die hoogste prys wees waarteen die voorraad verkoop kan word. Ná die eerste prysverlaging sal die prys $P_{2}$ wees, ensovoorts. Gestel die vraag (verkoopstempo) na 'n produk kan oor 'n gegewe tydsverloop gemodelleer word deur middel van 'n kromme, $D\left(P_{i}, t\right)$. Omdat die prys van items in voorraad nie afgemerk gaan word voordat die vraag na daardie items daal nie, sal $D\left(P_{i}, t\right)$ dus altyd 'n dalende funksie wees gedurende die tydperk wanneer prysverlagings oorweeg word. Die funksie na die $i$-de prysverlaging word gegee deur $D\left(P_{i+1}, t\right)$. Die volgende tye is van belang. Die tydstip wanneer die laaste aankoop deur die handelaar gemaak is, is $t_{a}$ en die tydstip wanneer die laaste bestelling betaal moet word, is $t_{b}$. Gestel $T$ is 'n tyd in die toekoms. Tydstip $T_{0}$ is wanneer die vraag na die items in voorraad gaan uitsterf, en die huidige oomblik (of nultydstip) is $t_{0}$. Die verwagte aantal verkope teen prys $P_{i}$ is $\phi\left(P_{i}\right)$ en die verwagte verkope teen prys $P_{i+1}$ is $\phi\left(P_{i+1}\right)$. Laat $I_{h}$ die huidige voorraadvlak wees, en $n$ die aantal datapunte wat gebruik word om die verwagte vraagkromme te bereken.

In die meeste gevalle waar die werklikheid met wiskundig gemodelleer word, moet 'n aantal aannames gemaak word. Die volgende aannames word in hierdie model gemaak:

1. Die hoeveelheid afslag wat toegestaan word, is vas. Die standaardprysverlagings in die bedryf word gebruik. Dieselfde aanname word ook gemaak in modelle waar die afmerk van byvoorbeeld vlugkaartjies beskou word [5].

2. Die vraag na 'n CD daal indien die helling van die kleinste-kwadrate-passing op die daaglikse verkope van 'n CD vir die afgelope $n$ dae negatief is.

3. Die verkoopsvolume styg oombliklik volgens die pryselastisiteit na die vraag (hierna pryselastisiteit genoem) sodra die prys verlaag word.

4. Aanvaar $D^{\prime}\left(P_{i}, t_{p}\right)=D^{\prime}\left(P_{i+1}, t_{p}\right)$ indien die prysverandering by tydstip $t_{p}$ plaasvind. Dit beteken dat die tempo waarteen die verkope net voor en net na die prysverlaging daal, dieselfde is.

Die historiese data oor die verkope van die item onder beskouing kan gebruik word om op 'n gepaste funksie vir $D\left(P_{i}, t\right)$ te besluit. Die funksie $D\left(P_{i}, t\right)$ word elke dag met die laaste $n$ dae se verkoopsyfers bereken. In werklikheid kan dit gebeur dat $D^{\prime}\left(P_{i}, t\right) \neq D^{\prime}\left(P_{i+1}, t\right)$. Die manier van berekening wat hier voorgestel word sal egter die fout wat met die aanname gemaak word van die volgende dag $\left(t_{p+1}\right)$ af begin korrigeer omdat dit die data ná die prysverandering in berekening bring in die bepaling van die vraagkromme, tot die helling na $n$ dae heeltemal met die verkope na die prysverandering bereken word en die aanname dus geen invloed meer het nie. Voor die prysverandering word die funksie $D\left(P_{i}, t\right)$ gebruik om die verkope te benader en ná die prysverandering word $D\left(P_{i+1}, t\right)$ gebruik. $D\left(P_{i+1}, t\right)$ word met behulp van die pryselastisiteit, $e_{p}$, bereken.

Vir die gebruik van die heuristiese algoritmes kan items in voorraad in drie kategorieë verdeel word: 
Groen Kategorie: Voorraad wat in hierdie kategorie val, kan teen die huidige prys op die rakke gehou word, omdat die verwagte verkoopsvolume teen die huidige prys meer as die huidige voorraadvlak is.

ORANJE KATEGORIE: Indien 'n item in hierdie kategorie val, beteken dit dat die handelaar versigtig moet wees en dat die prys van die item onder beskouing verlaag moet word om verliese te vermy. Items wat in hierdie kategorie val se verwagte verkoopsvolume teen die huidige prys is minder as die huidige voorraadvlak, maar die verwagte verkoopsvolume teen die laer prys is meer as die huidige voorraadvlak.

RoOI KATEGORIE: In hierdie geval het die vraag reeds só ver gedaal dat selfs 'n prysverlaging nie meer 'n verlies kan keer nie. Items wat in hierdie kategorie val, is waarskynlik geskik vir 'n uitverkoping.

Die idee agter hierdie kategoriee is dat indien die voorraad in die groen kategorie val, die handelaar kan voortgaan met die prys waarteen die CD op die oomblik op die rak is. Indien die CD van die groen na die oranje kategorie oorgaan beteken dit dat die handelaar die prys van die CD moet verlaag omdat al die voorraad in die winkel, na beraming, nie meer teen die huidige prys sal verkoop nie. Die rooi kategorie moet vermy word, want indien 'n CD in hierdie kategorie val, beteken dit dat verliese, na beraming, onafwendbaar is.

Die volgende twee heuristiese algoritmes kan in die algemeen geformuleer word. Algoritme 1 is in samewerking met die bestuurder van 'n CD-winkel ontwikkel, omdat die bestuurder (a) gevoel het dat hy op grond van ondervinding 'n goeie skatting kan maak oor wanneer 'n CD se verkope sal uitsterf (tydstip $T_{0}$ ), veral indien die verkope reeds laag gedaal het en (b) hy graag "wat indien"-vrae wou beantwoord deur die waarde van $T_{0}$ te varieer. Die rasionaal agter hierdie benadering is dat as die bestuurder $T_{0}$ kan verskaf, kan die verwagte hoeveelheid CD's wat nog verkoop kan word, bereken word. Indien die verwagte hoeveelheid CD's wat nog verkoop sal word meer as die huidige voorraad is, kan die prys stabiel gehou word en indien die huidige voorraad meer as die verwagte verkoopsvolume is, moet die pryse verlaag word.

\section{Algoritme 1}

Aan die einde van elke dag se verkope moet die volgende stappe uitgevoer word.

1. Doen 'n passing op die laaste $n$ datapunte om $D\left(P_{i}, t\right)$ te bepaal. Bereken die funksie $D\left(P_{i+1}, t\right)$. Hierdie funksies sal dan volgens aannames 3 en 4 die volgende eienskappe $h \hat{e}:$

$$
\begin{aligned}
D^{\prime}\left(P_{i}, t_{0}\right) & =D^{\prime}\left(P_{i+1}, t_{0}\right), \text { en } \\
D\left(P_{i+1}, t_{0}\right) & =D\left(P_{i}, t_{0}\right)+e_{p}\left(P_{i}-P_{i+1}\right) \frac{D\left(P_{i}, t_{0}\right)}{P_{i}} .
\end{aligned}
$$

2. Bereken die verwagte verkope oor die interval $\left[t_{0}, T\right]$ teen die prys $P_{i}$ :

$$
\phi\left(P_{i}\right)=\int_{t_{0}}^{T} D\left(P_{i}, t\right) \mathrm{d} t
$$


Bereken die verwagte verkope oor die interval $\left[t_{0}, T\right]$ teen die prys $P_{i+1}$ :

$$
\phi\left(P_{i+1}\right)=\int_{t_{0}}^{T} D\left(P_{i+1}, t\right) \mathrm{d} t .
$$

3. Gebruik $\phi\left(P_{i}\right), \phi\left(P_{i+1}\right)$ en $I_{h}$ om die voorraad in een van die drie kategorieë hieronder te plaas.

(a) Groen Kategorie

Voorraad waarvoor $\phi\left(P_{i}\right) \geq I_{h}$ val in hierdie kategorie.

(b) Oranje Kategorie

Indien $\phi\left(P_{i}\right)<I_{h}$ en $\phi\left(P_{i+1}\right) \geq I_{h}$ val voorraad in hierdie kategorie.

(c) Rooi Kategorie

Indien $\phi\left(P_{i}\right)<I_{h}$ en $\phi\left(P_{i+1}\right)<I_{h}$ val voorraad in hierdie kategorie.

Die waarde vir $T_{0}$ word gekies, wat beteken dat Algoritme 1 die nadeel het dat 'n menslike bydrae vereis word. Algoritme 2 is ontwikkel sodat geen inset van die bestuurder nodig is nie. Die rasionaal agter hierdie algoritme is om die punt te bereken waar die voorraaddrakoste gelyk aan die wins van die item in voorraad is. Dit is dus die punt waarna die item nie meer teen 'n wins verkoop kan word nie. Die verwagte vraagkromme kan dan gebruik word om te bepaal of die huidige voorraad voor hierdie punt uitverkoop sal word. Indien dit nie gaan gebeur nie, moet die prys verlaag word; sodat die voorraad vinniger kan verkoop. Hierdie algoritme het weer die nadeel dat 'n voorraaddrakoste bereken moet word, wat in die algemeen nie maklik is nie.

\section{Algoritme 2}

Aan die einde van elke dag se verkope moet die volgende stappe uitgevoer word.

1. Bereken die tydstip, $T\left(P_{i}\right)$, waarop die voorraaddrakoste só hoog gestyg het dat die wins op die item in voorraad, nul is. Doen ' $n$ passing op die laaste $n$ datapunte om $D\left(P_{i}, t\right)$ te bepaal. Bereken die funksie $D\left(P_{i+1}, t\right)$. Hierdie funksie sal dan volgens aannames 3 en 4 die volgende eienskappe hê:

$$
\begin{aligned}
D^{\prime}\left(P_{i}, t_{0}\right) & =D^{\prime}\left(P_{i+1}, t_{0}\right), \text { en } \\
D\left(P_{i+1}, t_{0}\right) & =D\left(P_{i}, t_{0}\right)+e_{p}\left(P_{i}-P_{i+1}\right) \frac{D\left(P_{i}, t_{0}\right)}{P_{i}} .
\end{aligned}
$$

2. Bereken die verwagte tydstip, $T^{0}\left(P_{i}\right)$, wanneer die voorraad teen die huidige prys uitverkoop sal wees. Dit wil sê, bereken

$$
I_{h}=\int_{0}^{T^{0}\left(P_{i}\right)} D\left(P_{i}, t\right) \mathrm{d} t .
$$

Bereken ook die verwagte tydstip, $T^{0}\left(P_{i+1}\right)$, wanneer die voorraad teen 'n prys van $P_{i+1}$ uitverkoop sal wees. Dit wil sê, bereken

$$
I_{h}=\int_{0}^{T^{0}\left(P_{i+1}\right)} D\left(P_{i+1}, t\right) \mathrm{d} t .
$$


3. Gebruik $T\left(P_{i}\right), T^{0}\left(P_{i}\right)$ en $T^{0}\left(P_{i+1}\right)$ om die voorraad in een van die drie kategorieë hieronder te plaas.

(a) Groen Kategorie

Die items in voorraad val in hierdie kategorie indien $T^{0}\left(P_{i}\right) \leq T\left(P_{i}\right)$.

(b) Oranje Kategorie

Die items in voorraad val in hierdie kategorie indien $T^{0}\left(P_{i}\right)>T\left(P_{i}\right)$ en $T^{0}\left(P_{i+1}\right) \leq T\left(P_{i+1}\right)$.

(c) Rooi KATEGORIE

Die items in voorraad val in hierdie kategorie indien $T^{0}\left(P_{i}\right)>T\left(P_{i}\right)$ en $T^{0}\left(P_{i+1}\right)>T\left(P_{i+1}\right)$.

\section{Gevallestudie}

Die probleem met die toetsing van die model wat hierbo voorgestel word, is dat net een afmerkstrategie in die praktyk getoets kan word - eenvoudig omdat dieselfde item wat teen twee verskillende pryse in dieselfde winkel is, net teen die laer prys sal verkoop. Dit is dus onmoontlik om in die praktyk te toets of die model hierbo se antwoorde beter resultate lewer as byvoorbeeld die bestuurder se afmerkstrategieë. Hierdie probleem word oorkom deur van simulasie gebruik te maak. Die bestuurder kan dan prysstrategieë uitoefen, terwyl die model se prysstrategieë parallel daaraan getoets kan word. Die prestasie van die bestuurder, sowel as elkeen van die modelle, kan dan teen mekaar getoets word. In die gevallestudie is met die werklike data van 'n CD-winkel gewerk om 'n realistiese vraag in die simulasie te gegenereer. Die simulasie is met behulp van Microsoft Excel gedoen.

Die resultate met $D\left(P_{i}, t\right)$ as twee verskillende tipes funksies word verskaf. Die afleiding word egter net vir die 'n eksponensiële funksie gemaak. Die afleiding vir ander funksies volg soortgelyk. Indien die aanname gemaak word dat die vraag eksponensieel uitsterf (soos wat die geval is met eksponensiële verval), kan die algemene eksponensiële vorm

$$
D\left(P_{i}, t\right)=\alpha e^{\beta t}
$$

gekies word. Die volgende metodes kan gebruik word om $\alpha$ en $\beta$ te benader. Laat $t_{0}$ gelyk aan 0 en $n$ gelyk aan $w$ wees. Die eerste metode om $\alpha$ en $\beta$ te bepaal sou wees om bloot die kleinste-kwadrate-passing op die laaste $w$ punte getransformeer na $\left(t_{i}, \ln \left(x_{i}\right)\right)$ te doen (sien die resultate in Tabel 2). 'n Ander metode is om die gemiddelde verkope van die afgelope $w$ tydsperiodes, $\left(\bar{x}_{w}\right)$, te gebruik om die $y$-afsnit van $D\left(P_{i}, t\right)$ te bepaal. Dus sal $\alpha=\bar{x}_{w}$. Indien 'n kleinste-kwadrate-regressielyn op die mees onlangse data gedoen word, kan die helling van hierdie lyn $(m)$ gebruik word om die tempo waarteen die vraag uitsterf, te benader. Die gepaste vergelyking vir $m$, indien $x_{i}$ die waargenome verkope op tydstip $t_{i}$ is, is

$$
m=\frac{\sum_{i=1}^{n} t_{i} x_{i}-\frac{1}{n} \sum_{i=1}^{n} t_{i} \sum_{i=1}^{n} x_{i}}{\sum_{i=1}^{n} t_{i}^{2}-\frac{1}{n}\left[\sum_{i=1}^{n} t_{i}\right]^{2}} .
$$


Weer eens sal die lengte van die periode (dus $n$ in vergelyking (5)) waaroor die regressielyn gepas word, deur die data bepaal word. Die tempo waarteen die vraag op tydstip $t_{0}$ uitsterf, kan dus benader word deur $D^{\prime}(0)=m$. Hieruit volg dat

$$
\beta=\frac{m}{\bar{x}_{w}} .
$$

Die eksponensiële vorm van die vraagkromme word dus gegee deur

$$
D(t)=\bar{x}_{w} e^{\frac{m}{\bar{x}_{w}} t} .
$$

Die resultate indien $\alpha$ deur die $y$-afsnit van die kleinste-kwadrate-lyn benader word, word ook gegee.

Die aanname van 'n eksponensiële aanvraagkromme lewer die volgende spesiale gevalle van die heuristieke wat in $\S 3$ bespreek is.

\section{Algoritme $\mathbf{1}^{\prime}$}

Aan die einde van elke dag se verkope kan die volgende bewerkings vinnig uitgevoer word:

1. Bepaal $m$ en $\bar{x}_{w}$. Kies die waarde van $T_{0}$.

2. Bepaal die verwagte verkope, $\phi\left(P_{i}\right)$, teen prys $P_{i}$ as

$$
\phi\left(P_{i}\right)=\int_{0}^{T_{0}} \bar{x}_{w} e^{\frac{m}{\bar{x}_{w}} t} \mathrm{~d} t,
$$

sodat

$$
\phi\left(P_{i}\right)=\frac{\bar{x}_{w}^{2}}{m}\left[e^{\frac{m}{\overline{x_{w}}} T_{0}}-1\right] .
$$

Bepaal die verwagte vraag, $\phi\left(P_{i+1}\right)$, teen prys $P_{i+1}$, met die onderstaande integraal. Indien die voorraad 'n pryselastisiteit van $e_{p}$ het, sal die vraagkromme die $y$-as sny by

$$
\alpha=\bar{x}_{w}+e_{p}\left(P_{i}-P_{i+1}\right) \frac{\bar{x}_{w}}{P_{i}} .
$$

Stel hierdie waarde vir $\alpha=\eta$ en stel dit terug in die integraal in (6); dan word die verwagte verkope gegee deur

$$
\phi\left(P_{i+1}\right)=\int_{0}^{T_{0}} \eta e^{\frac{m}{\eta} t} \mathrm{~d} t .
$$

Hieruit volg dat

$$
\phi\left(P_{i+1}\right)=\frac{\eta^{2}}{m}\left[e^{\frac{m}{\eta} T_{0}}-1\right] .
$$

3. Gebruik $\phi\left(P_{i}\right), \phi\left(P_{i+1}\right)$ en $I_{h}$ om die voorraad in een van die drie kategorieë hieronder te plaas.

\section{(a) Groen Kategorie}

Voorraad waarvoor $\phi\left(P_{i}\right) \geq I_{h}$ val in hierdie kategorie, waar $\phi\left(P_{i}\right)$ die verwagte verkope teen prys $P_{i}$ is. 
(b) ORAnje Kategorie

Indien $\phi\left(P_{i}\right)<I_{h}$ en $\phi\left(P_{i+1}\right) \geq I_{h}$ val voorraad in hierdie kategorie.

(c) Rooi KATEGorie

Indien $\phi\left(P_{i}\right)<I_{h}$ en $\phi\left(P_{i+1}\right)<I_{h}$ val voorraad in hierdie kategorie.

\section{Algoritme 2'}

Aan die einde van elke dag se verkope kan die volgende bewerkings vinnig uitgevoer word:

1. Bepaal $m, \bar{x}_{w}$ en $T\left(P_{i}\right)$.

2. Bepaal $T^{0}\left(P_{i}\right)$ met behulp van die volgende integraal:

$$
I_{h}=\int^{T^{0}\left(P_{i}\right)} \bar{x}_{w} e^{\frac{m}{\bar{x}_{w}} t} \mathrm{~d} t
$$

Hieruit volg dat

$$
T^{0}\left(P_{i}\right)=\frac{\bar{x}_{w}}{m} \ln \left[\frac{m I_{h}}{\bar{x}^{2}}+1\right] .
$$

Indien $\eta$ dieselfde betekenis as in Algoritme $1^{\prime}$ het, volg dat $T^{0}\left(P_{i+1}\right)$ gegee word deur

$$
T^{0}\left(P_{i+1}\right)=\frac{\eta}{m} \ln \left[\frac{m I_{h}}{\eta^{2}}+1\right] .
$$

3. Gebruik $T\left(P_{i}\right), T^{0}\left(P_{i}\right)$ en $T^{0}\left(P_{i+1}\right)$ om die voorraad in een van die drie kategorieë hieronder te plaas.

(a) Groen Kategorie

Die items in voorraad val in hierdie kategorie indien $T^{0}\left(P_{i}\right) \leq T\left(P_{i}\right)$.

(b) Oranje Kategorie

Die items in voorraad val in hierdie kategorie indien $T^{0}\left(P_{i}\right)>T\left(P_{i}\right)$ en $T^{0}\left(P_{i+1}\right) \leq T\left(P_{i+1}\right)$.

(c) Rooi Kategorie

Die items in voorraad val in hierdie kategorie indien $T^{0}\left(P_{i}\right)>T\left(P_{i}\right)$ en $T^{0}\left(P_{i+1}\right)>T\left(P_{i+1}\right)$.

Die bestuurder se prysverlagingstrategie bly altyd dieselfde. Die eerste prysverlaging word gegee op tydstip $t_{b}$. Indien die CD dertig dae ná $t_{b}$ nog nie uitverkoop is nie, word die voorraad vir die tweede keer afgemerk. Al die simulasielopies is met die volgende beginwaardes gedoen. Die laaste bestelling het teen tydstip $t=4$ opgedaag. Al die vorige bestellings word geïgnoreer omdat ons kan aanvaar dat vorige bestellings almal betyds uitverkoop het, anders sou die bestuurder nie die laaste bestelling gemaak het nie. Die betaaldatum word lukraak bepaal as 'n tyd $54 \leq t \leq 64$ (in werksdae). Die keuse hiervoor is omdat die bestuurder altyd bestellings in die laaste week van 'n maand plaas om seker te maak dat die volle 60 dae-betaaltydperk gebruik word. Die verkoopprys vir 'n nuwe CD word op R120 gestel. Die eerste afslag is R20 en die tweede afslag is weer R20. Indien die CD steeds nie verkoop nie, word die prys nie weer aangepas nie. Die voorraaddrakoste 
is ongeveer R0,45 per CD per dag en die pryselastisiteit van 'n CD word op 1,5 gestel [22]. Dit is nie moontlik om die pryselastisiteit van 'n produk in 'n tabel op te soek nie. Die pryselastisiteit is omgewing (kliënt) spesifiek en moet daarom vir elke winkel individueel bepaal word [15]. 'n Jaar se volledige data (alle kostes, verkope, ensovoorts) van die CD-winkel wat in hierdie gevallestudie gebruik is, is bekom en in Labuschagne en Meyer (2001) se studie gebruik om hierdie twee groothede vas te stel. In die jaar se data tot hulle beskikking is 23 CD's afgemerk. Die pryselastisiteit van elk van hierdie CD's is bereken, en die gemiddelde pryselastisiteit vir al hierdie CD's is bepaal. Labuschagne en Meyer gebruik die definisie van pryselastisiteit soos dit in Mohr et al. (1996) gepubliseer is. Volgens hierdie definisie, word die pryselastisiteit gegee deur

$$
e_{p}=\frac{\text { proporsionele verandering in die hoeveelheid gevra }}{\text { proporsionele verandering in die prys }}=\frac{\frac{\Delta Q}{Q}}{\frac{\Delta P}{P}},
$$

waar $Q$ die gemiddelde aantal verkope vóór en ná die prysverandering is, $\Delta Q$ die verskil tussen die aantal verkope vóór en ná die prysverandering is, $P$ die gemiddelde prys vóór en ná die prysverandering is, en $\Delta P$ die verskil tussen die pryse vóór en ná die prysverandering is. As numeriese voorbeeld kan die CD Okay Computer van Radiohead gebruik word [22]. Die prys van hierdie CD is van R119 na R79 afgemerk, wat die verkope van 1 na 2 CD's per week laat toeneem het. Dit lewer 'n pryselastisiteit van

$$
e_{p}=\frac{\frac{1}{1,5}}{\frac{40}{99}}=1,65
$$

Die bepaling van 'n voorraaddrakoste regverdig 'n studie opsigself. Labuschagne en Meyer het die bepaling van die voorraaddrakoste gebaseer op die riglyne in vier boeke deur Coyle et al. (1996), Ballou (1999), Lambert et al. (1998) en Water (1992) onderskeidelik. Die voorraadkoste bestaan uit vier basiese elemente, naamlik eenheidskoste, koste van bestellings, drakoste en uitvoorraadkoste. Die koste wat hier van belang is, is die drakoste. Die voorraaddrakoste kan opgedeel word in die kapitale koste, voorraaddienskoste, voorraadrisikokoste en stoorkoste. Indien al die kostes wat die CD winkel gedurende die jaar ondervind het, ingedeel word in al die tipes kostes, word 'n totale voorraaddrakoste van R92 333 verkry. Daar is verskillende maniere om hierdie koste toe te deel aan elke CD. Een manier sou wees om hierdie bedrag te deel deur al die CD's wat gedurende die jaar in voorraad gedra is, wat op 'n koste van ongeveer R0,86 per CD per dag neerkom. Hierdie metode is om twee redes nie 'n regverdige toedeling nie. Die CD's met 'n laer prys behoort 'n laer drakoste te absorbeer en die CD's met 'n vinniger verkoopstempo (byvoorbeeld populêre musiek) behoort 'n hoër voorraaddrakoste te absorbeer as CD's met 'n stadiger verkoopstempo (byvoorbeeld klassieke musiek). Hiervolgens kan die CD's dan volgens hulle omset in klasse verdeel word. Labuschagne en Meyer (2001) het drie klasse gedefinieer, naamlik CD's met 'n hoë omset, CD's met 'n gemiddelde omset en CD's met 'n lae omset. Aan hierdie drie klasse moet onderskeidelik 50\%, 30\% en $20 \%$ van die voorraaddrakoste toegedeel word. Volgens hierdie metode sal voorraad met 'n stadige omset ongeveer R0,45 per CD per dag wees.

Die resultate vir 40 simulasielopies, met die laaste bestelgrootte gelyk aan 100 items (dit is 100 weergawes van dieselfde CD), word in Tabelle 1 tot 3 weergegee. Die verliese in 
hierdie tabelle is die verliese wat die winkel ly as gevolg van CD's wat te lank op die rakke was (voorraaddrakoste is groter as die verkoopprys minus aankoopprys) of glad nie binne die simulasietydperk verkoop het nie. 'n Verlies van R120 (verkoopprys) plus die voorraaddrakoste word op elkeen van die CD's gehef, wat nie tydens die simulasielopie verkoop het nie. Die strategie van die bestuur is om die voorraad teen prys $P_{1}$ op die rak te plaas en dit dan op die betaaldatum $t_{b}$ af te merk met R20 na $P_{2}$. Indien die CD's ná nog 'n maand steeds nie verkoop is nie, word die prys verder verlaag met R20 na $P_{3}$. Die CD's word nie met meer as hierdie bedrag afgemerk nie.

\begin{tabular}{lccc}
\hline & Bestuur & Algoritme $1^{\prime}$ & ${\text { Algoritme } 2^{\prime}}$ \\
\hline Gemiddeld & 1639.51 & 970.80 & 1236.13 \\
Standaardafwyking & 1414.86 & 1261.01 & 1278.56 \\
$90 \%$ vertrouensinterval & {$[1378.28 ; 1900.74]$} & {$[711 ; 1230.60]$} & {$[971.72 ; 1498.54]$} \\
\hline
\end{tabular}

Tabel 1: Gemiddelde verliese (in rand) met $D\left(P_{i}, t\right)$ eksponensieel en $\alpha=\bar{x}_{w}$.

Indien dieselfde data gebruik word, maar die $\alpha$ deur y-afsnit van die kleinste-kwadrate-lyn benader word, word die resultate in Tabel 2 verkry.

\begin{tabular}{lccc}
\hline & Bestuur & Algoritme $1^{\prime}$ & ${\text { Algoritme } 2^{\prime}}^{\prime}$ \\
\hline Gemiddeld & 1639.51 & 1245.31 & 1327.94 \\
Standaardafwyking & 1414.86 & 1582.04 & 1566.41 \\
90\% vertrouensinterval & {$[1378.28 ; 1900.74]$} & {$[953.21 ; 1537.41]$} & {$[1038.72 ; 1617.16]$} \\
\hline
\end{tabular}

Tabel 2: Gemiddelde verliese (in rand) met $D\left(P_{i}, t\right)$ eksponensieel en $\alpha$ en $\beta$ gelyk aan die kleinste-kwadrate-passing van $\left(t_{i}, \ln \left(x_{i}\right)\right)$ se $y$-afsnit en helling.

Indien dieselfde eksperiment herhaal word met $D\left(P_{i}, t\right)$ gelyk aan 'n reguitlyn, word die resultate in Tabel 3 verkry.

\begin{tabular}{lccc}
\hline & Bestuur & Algoritme $1^{\prime}$ & Algoritme 2' \\
\hline Gemiddeld & 1639.51 & 1481.96 & 1522.83 \\
Standaardafwyking & 1414.86 & 1411.27 & 1498.14 \\
$90 \%$ vertrouensinterval & {$[1378.28 ; 1900.74]$} & {$[1221.39 ; 1742.53]$} & {$[1246.22 ; 1799.44]$} \\
\hline
\end{tabular}

Tabel 3: Gemiddelde verliese (in rand) met $D\left(P_{i}, t\right)$ lineêr.

Indien dieselfde randwaardes as vir die simulasie geld, kan die volgende as 'n numeriese voorbeeld dien van hoe Algoritme 1' toegepas kan word vir bostaande beginwaardes. Gestel die volgende daaglikse vraag is die afgelope 21 dae verkry: $7,4,9,8,4,7,7,9,5,6,8,6$, $6,4,5,5,5,6,3,3,5$. Hieruit volg dat $m=-0.13326$ (indien 'n lineêre regressie oor die tydperk gedoen word) en $\bar{x}_{w}=4.571429$ (indien $w$ gelyk aan 'n week gekies word). Gestel $T$ word as 84 gekies. Indien hierdie waardes in vergelyking (6) gestel word, volg dat die verwagte verkope vir die volgende 84 dae (van $t_{0}$ tot $T_{0}$ ) teen die huidige prys gegee word deur

$$
\phi\left(P_{i}\right)=\int_{0}^{84} 4.571 e^{\frac{-0.133}{4.571} t} \mathrm{~d} t=\frac{4.571^{2}}{-0.133}\left[e^{\frac{-0.133}{4.571} 84}\right]=143.2 .
$$


Om die verwagte verkope oor dieselfde tydperk met afslag te bereken, moet $\eta$ eers bereken word. Dit word gegee deur

$$
\eta=\bar{x}_{w}+e_{p}\left(P_{i}-P_{i+1}\right) \frac{\bar{x}_{w}}{P_{i}}=5.714 .
$$

Die verwagte verkope volg as

$$
\phi\left(P_{i+1}\right)=\frac{\eta^{2}}{m}\left[e^{\frac{m}{\eta} T}-1\right]=\frac{5.714^{2}}{-0.133}\left[e^{\frac{-0.133}{5.714} 84}-1\right]=210.483 .
$$

Dit plaas die voorraad in die groen kategorie omdat $I_{h}<\phi\left(P_{i}\right)$. Indien hierdie prosedure elke dag vir die volgende sewe dae herhaal word, word die data in Tabel 4 verkry.

\begin{tabular}{cccccccl}
\hline Tyd & Vraag/dag & $m$ & $\bar{x}_{w}$ & $I_{h}$ & $\phi\left(P_{i}\right)$ & $\phi\left(P_{i+1}\right)$ & Kategorie \\
\hline$t_{0}-7$ & 5 & -0.1333 & 4.5714 & 60 & 143.2717 & 210.4827 & Groen \\
$t_{0}-6$ & 2 & -0.1762 & 4.1429 & 55 & 94.5671 & 143.1835 & Groen \\
$t_{0}-5$ & 2 & -0.2016 & 3.7143 & 53 & 67.6395 & 103.8949 & Groen \\
$t_{0}-4$ & 3 & -0.2484 & 3.4286 & 51 & 47.1806 & 73.25324 & Oranje \\
$t_{0}-3$ & 3 & -0.2292 & 3 & 48 & 39.1717 & 60.88051 & Oranje \\
$t_{0}-2$ & 2 & -0.2282 & 2.8571 & 45 & 35.7198 & 55.55427 & Oranje \\
$t_{0}-1$ & 1 & -0.2840 & 2.5714 & 43 & 23.2767 & 36.33944 & Rooi \\
$t_{0}$ & 0 & -0.3094 & 1.8571 & 42 & 11.1462 & 17.4154 & Rooi \\
\hline
\end{tabular}

Tabel 4: Resultate vir Algoritme $1^{\prime}$.

Indien presies dieselfde data vir Algoritme $2^{\prime}$ gebruik word, moet

$$
T^{0}\left(P_{i}\right)=\frac{\bar{x}_{w}}{m} \ln \left[\frac{m I_{h}}{\bar{x}^{2}}+1\right]=\frac{4.571}{-0.133} \ln \left[\frac{(-0.133)(60)}{4.571^{2}}+1\right]=16.543
$$

en

$$
T^{0}\left(P_{i+1}\right)=\frac{\eta}{m} \ln \left[\frac{m I_{h}}{\eta^{2}}+1\right]=\frac{5.714}{-0.133} \ln \left[\frac{(-0.133)(60)}{5.714^{2}}+1\right]=12.043
$$

bereken word.

Indien hierdie proses vir die volgende sewe dae herhaal word, word die data in Tabel 5 verkry. (Vir hierdie data is $T\left(P_{i}\right)=95$ en $T\left(P_{i+1}\right)=41$. Die "-" in hierdie tabel beteken dat al word $T^{0}\left(P_{i}\right)=\infty$ gestel, die verwagte verkope nie meer as $I_{h}$ sal wees nie. Dit beteken dat $T^{0}\left(P_{i}\right)$ nie bereken kan word nie.)

\begin{tabular}{ccccccl}
\hline Tyd & Vraag/dag & $m$ & $\bar{x}_{w}$ & $\left.T^{(} P_{i}\right)$ & $T^{0}\left(P_{i+1}\right)$ & Kategorie \\
\hline$t_{0}-7$ & 5 & -0.1333 & 4.5714 & 16.5430 & 12.0434 & Groen \\
$t_{0}-6$ & 2 & -0.1762 & 4.1429 & 19.5504 & 13.1788 & Groen \\
$t_{0}-5$ & 2 & -0.2016 & 3.7143 & 27.4372 & 15.7641 & Groen \\
$t_{0}-4$ & 3 & -0.2484 & 3.4286 & - & 20.1948 & Oranje \\
$t_{0}-3$ & 3 & -0.2292 & 3 & - & 24.9549 & Oranje \\
$t_{0}-2$ & 2 & -0.2282 & 2.8571 & - & 25.5780 & Rooi \\
$t_{0}-1$ & 1 & -0.2840 & 2.5714 & - & - & Rooi \\
$t_{0}$ & 0 & -0.3094 & 1.8571 & - & - & Rooi \\
\hline
\end{tabular}

Tabel 5: Resultate vir Algoritme $2^{\prime}$. 


\section{$5 \quad$ Gevolgtrekkings en verdere navorsing}

Uit Tabel 1 blyk duidelik dat die verlies vir die laaste bestelling gemiddeld R1 640 is teenoor R971 vir Algoritme 1' en R1 236 vir Algoritme 2'. Dit beteken dat Algoritme 1' gemiddeld $40.79 \%$ en Algoritme $2^{\prime}$ gemiddeld $24.60 \%$ minder verliese lewer as die bestuurder se huidige strategie. Indien die resultate in Tabelle 1 tot 3 met mekaar vergelyk word, is dit duidelik dat die keuse van $D\left(P_{i}, t\right)$ soos in Algoritmes $1^{\prime}$ en $2^{\prime}$ die beste resultate lewer vir die data van die betrokke CD-winkel.

Die groot tekortkoming van albei hierdie modelle is dat hulle net verliese beperk. 'n Volgende stap kan wees om die maksimering van wins as die hoofdoelwit te te gebruik. Dit kan heel moontlik gebeur dat verliese beperk word, maar in die proses om verliese te beperk, soveel korting toegestaan word dat die wins ook noemenswaardig krimp. 'n Ander faktor wat in verdere studies aandag kan geniet, is die effek van rente op die wins/verlies van die items. Die effek van rente is egter só klein (omdat die rekeninge van die bestellings eers na 60 dae betaalbaar is) in vergelyking met ander koste dat dit weglaatbaar is. In die praktyk gebeur dit uiters selde dat voorraad vir langer as 120 dae in die winkel bly. Om hierdie rede is rente nie hier in berekening gebring nie.

'n Probleem wat nie hier ondersoek word nie, maar wat ook aandag moet geniet, is die bedrag waarmee 'n CD afgemerk moet word, sowel as die aantal keer wat die prys afgemerk moet word. Dit bly 'n ope vraag of een groot afslag beter is as 'n aantal kleiner prysverlagings.

\section{Verwysings}

[1] Aват PL, 2003, Optimal pricing and lot-sizing under conditions of perishability, finite production and partial backordering and lost sales, European Journal of Operational Research, 144(3), pp. 677-685.

[2] Ballou RH, 1999, Business logistics management, Prentice Hall, Englewood Cliffs $(\mathrm{NJ})$.

[3] Bitran G, Caldentey R \& Mondschein SV, 1998, Coordinating clearance markdown sales of seasonal products in retail chains, Operations Research, 46(5), pp. 609-624.

[4] Bitran G \& Mondschein SV, 1997, Periodic pricing of seasonal products in retailing, Management Science, 43(1), pp. 64-79.

[5] Chatwin RE, 2000, Optimal dynamic pricing of perishable products with stochastic demand and a finite set of prices, European Journal of Operational Research, 125(1), pp. 149-174.

[6] Cobbaert K \& Oudheusden DV, 1996, Inventory models for fast moving spare parts subject to "sudden death" obsolescence, International Journal of Production Economics, 44(3), pp. 239-248. 
[7] Coyle JJ, Bardi EJ \& Langley CJ, 1996, The management of business logistics, $6^{\text {de }}$ Uitgawe, West Publishing Company, Minneapolis (MN).

[8] Deneckere R, Marvel HP \& Peck J, 1997, Demand uncertainty and price maintenance: Markdown as destructive competition, The American Economic Review, 87(4), pp. 619-641.

[9] Federgruen A \& Heching A, 1999, Combined pricing and inventory control under uncertainty, Operations Research, 47(3), pp. 454-475.

[10] Feng Y \& Gallego G, 1995, Optimal starting times for end-of-season sales and optimal stopping times for promotional fares, Management Science, 41(8), pp. 13711391.

[11] Gallego G \& Van Ryzin G, 1997, A multiproduct dynamic pricing problem and its application to network yield management, Operations Research, 45(1), pp. 24-41.

[12] Ghare PN \& Schrader S, 1963, A model for exponentially decaying inventories, Journal of Industrial Engineering, 15, pp. 238-243.

[13] GOYAL SK \& GIRI BC, 2001, Recent trends in modeling of deteriorating inventory, European Journal of Operational Research, 134(1), pp. 1-16.

[14] JAIN K \& Silver EA, 1994, Lot sizing for a product subject to obsolescence or perishability, European Journal of Operational Research, 75(2), pp. 287-295.

[15] Hoch SJ, Kim B, Montgomery AL \& Rossi PE, 1995, Determinants of storelevel price elasticity, Journal of Marketing Research, 32(2), pp. 17-29.

[16] Kalpakam S \& Arivarignan G, 1988, A continuous review perishable inventory model, Statistics, 19, pp. 389-398.

[17] Kalpakam S \& SaPna KP, 1994, Continuous review $(s, S)$ inventory system with random lifetimes and positive leadtimes, Operations Research Letters, 16(2), pp. $115-119$.

[18] Kalpakam S \& SAPna KP, 1995, $(S-1, S)$ perishable systems with stochastic leadtimes, Mathematical and Computer Modelling, 21(6), pp. 95-104.

[19] Kalpakam S \& Sapna KP, 1996, A lost sale $(S-1, S)$ parishable inventory system with renewable demand, Naval Research Logistics, 43(1), pp. 129-142.

[20] Kincaid WM \& Darling DA, 1963, An inventory pricing problem, Journal of Mathematical Analysis and Applications, 7, pp. 183-208.

[21] Kopalle PK, Mela CF \& Marsh L, 1999, The dynamic effect of discounting on sales: Empirical analysis and normative pricing implications, Marketing Science, 18(3), pp. 317-332.

[22] Labuschagne A \& Meyer P, 2001, Toedeling van voorraad- en bedryfskostes van 'n CD winkel, Honneursseminaar, Universiteit van Stellenbosch, Stellenbosch. 
[23] Lambert DM, Stock JR \& Ellram LM, 1998, Fundamentals of logistics management, Irwan McGraw-Hill, Boston (MA).

[24] Lazear EP, 1986, Retail pricing and clearance sales, The American Economic Review, 76(1), pp. 14-32.

[25] LIU L, 1990, $(s, S)$ continuous review models for inventory with random lifetimes, Operations Research Letters, 9(3), pp. 161-167.

[26] Liu L \& Cheung KL, 1997, Constraint inventory models with random lifetimes and lead times, Journal of the Operational Research Society, 48, pp. 1022-1028.

[27] LiU L \& SHI DH, 1999, An $(s, S)$ model for inventory with exponential lifetimes and renewal demands, Naval Research Logistics, 46(1), pp. 39-56.

[28] Manthrala MK \& RAO S, 2001, A decision support system that helps retailers decide order quantities and markdowns for fashion goods, Interfaces, 31(3), pp. S146S165.

[29] Miller BL, 1968, Finite state continuous time Markov decision processes with a finite planing horizon, SIAM Journal of Control, 6, pp. 266-280.

[30] Mohr P, Fourie L, ET AL, 1996, Ekonomie vir Suid-Afrikaanse studente, JL van Schaik Uitgewers, Pretoria.

[31] Moorthy KA, Narasimhulu YC \& Basha IR, 1992, On perishable inventory with Markov chain demand quantities, International Journal of Information Management Science, 3, pp. 29-37.

[32] Nahmias S, 1982, Perishable inventory: Review, Operations Research, 30(4), pp. 680-708.

[33] SEzen B, 2004, Expected profit approach used in discount pricing decisions for perishable products, International Journal of Retail \& Distribution Management, 32(2), pp. 223-229.

[34] Smith SA \& Achabal DD, 1998, Clearance pricing and inventory policies for retail chains, Management Science, 44(3), pp. 285-300.

[35] Water CDJ, 1992, Inventory control and management, John Wiley \& Sons, New York (NY).

[36] WeE HM \& Yu J, 1997, A deteriorating inventory with a tempory price discount, International Journal of Production Economics, 53, pp. 81-90.

[37] Whitin TM, 1957, Theory of inventory management, Princeton University Press, Princeton (NJ). 
